\title{
Pregnancy in Pompe disease
}

\author{
Ursula Plöckinger \\ From Proceedings of the 6th European Symposium: Steps Forward in Pompe Disease \\ Berlin, Germany. 23-24 November 2012
}

Pregnancy in Pompe disease is still a rare event. Only few reports have been published. Physiological changes of pregnancy may be aggravated by Pompe disease or vice versa. Both may pose a risk for the mother and the unborn child. This talk outlines physiological changes of the cardiovascular, respiratory and hormonal system during pregnancy and delineates the impact on a 36-year-old Pompe patient with a twin pregnancy. Furthermore, recommendations for a prospective medical strategy are presented and a workflow for routine follow-up during pregnancy is suggested. Recommendations include the planning of the pregnancy, genetic counselling, and prepregnancy investigations. An interdisciplinary team consisting of an obstetrician, pulmonologist, internist, endocrinologist and anaesthesiologist is suggested for care of the pregnant patient with Pompe disease.

Published: 29 May 2013

doi:10.1186/1471-2474-14-S2-O11

Cite this article as: Plöckinger: Pregnancy in Pompe disease. BMC

Musculoskeletal Disorders 2013 14(Suppl 2):O11.

Submit your next manuscript to BioMed Central and take full advantage of:

- Convenient online submission

- Thorough peer review

- No space constraints or color figure charges

- Immediate publication on acceptance

- Inclusion in PubMed, CAS, Scopus and Google Scholar

- Research which is freely available for redistribution 